\title{
Differences in Airway Inflammation in Patients with Fixed Airflow Obstruction Due to Asthma or Chronic Obstructive Pulmonary Disease
}

\author{
Leonardo M. Fabbri, Micaela Romagnoli, Lorenzo Corbetta, Gianluca Casoni, Kamelija Busljetic, \\ Graziella Turato, Guido Ligabue, Adalberto Ciaccia, Marina Saetta, and Alberto Papi
}

Research Center on Asthma and COPD, University of Ferrara, Italy; Departments of Respiratory Diseases and Radiology, University of Modena \& Reggio Emilia, Modena, Italy; Department of Respiratory Medicine, University of Skopje, Macedonia; Section of Respiratory Diseases, Department of Clinical and Experimental Medicine, University of Padova, Italy

To determine whether patients with fixed airflow obstruction have distinct pathologic and functional characteristics depending on a history of either asthma or chronic obstructive pulmonary disease (COPD), we characterized 46 consecutive outpatients presenting with fixed airflow obstruction by clinical history, pulmonary function tests, exhaled nitric oxide, sputum analysis, bronchoalveolar lavage, bronchial biopsy, and high-resolution computed tomography chest scans. Subjects with a history of COPD $(n=27)$ and subjects with a history of asthma $(n=19)$ had a similar degree of fixed airflow obstruction ( $\mathrm{FEV}_{1}: 56 \pm 2$ versus $56 \pm 3 \%$ predicted) and airway hyperresponsiveness $\left(\mathrm{PC}_{20} \mathrm{FEV}_{1}: 2.81\right.$ [3.1] versus 1.17 [3.3]). Subjects with a history of asthma had significantly more eosinophils in peripheral blood, sputum, bronchoalveolar lavage, and airway mucosa; fewer neutrophils in sputum and bronchoalveolar lavage fluid; a higher CD4+/CD8 + ratio of T cells infiltrating the airway mucosa; and a thicker reticular layer of the epithelial basement membrane. They also had significantly lower residual volume, higher diffusing capacity, higher exhaled nitric oxide, lower high-resolution computed tomography scan emphysema score, and greater reversibility to bronchodilator and steroids. In conclusion, despite similar fixed airflow obstruction, subjects with a history of asthma have distinct characteristics compared with subjects with a history of COPD and should be properly identified and treated.

Keywords: smoking; eosinophil; nitric oxide; bronchitis; emphysema

Patients with fixed airflow obstruction are often grouped under the heading of chronic obstructive pulmonary disease (COPD), and some international guidelines $(1,2)$ recommend classifying asthma with fixed airflow obstruction as COPD. Indeed, both COPD (induced by smoking or other noxious agents) and asthma may be associated with a decline of lung function that causes fixed airflow obstruction (3-6). As lung function is not routinely measured, airflow obstruction is largely underestimated, particularly in the elderly (7). It may be recognized only when patients present with respira-

(Received in original form March 7, 2002; accepted in final form October 24, 2002) This work was supported by the Italian Ministry of Education (MURST 40\%), European Community (Biomed 2 Research Project "BIOAIR," Contract BMH4CT96-1471), Associazione per la Ricerca e Cura dell' Asma (A.R.C.A.), Padova, and a special grant from GlaxoSmithKline, Verona, Italy. Dr. Kamelija Busljetic was the recipient of an International Fellowship from the European Respiratory Society to the University of Ferrara, Italy.

Correspondence and requests for reprints should be addressed to Leonardo $\mathrm{M}$. Fabbri, Department of Respiratory Diseases, University of Modena \& Reggio Emilia, Policlinico, Via del Pozzo, 71, 41100 Modena, Italy. E-mail: fabbri.leonardo@ unimo.it

This article has an online supplement, which is accessible from this issue's table of contents online at www.atsjournals.org

Am J Respir Crit Care Med Vol 167. pp 418-424, 2003

Originally Published in Press as DOI: 10.1164/rccm.200203-1830C on November 8, 2002 Internet address: www.atsjournals.org tory symptoms after airflow obstruction is already fixed. These patients are often diagnosed as having COPD, even if the differential diagnosis between asthma and COPD in patients with fixed airflow obstruction may be important as the natural history (8) as well as the response to treatment (9) are different, depending on whether fixed airflow obstruction is due to asthma or COPD. Epidemiologic studies have demonstrated that up to $30 \%$ of patients with fixed airflow limitation have a history of asthma (10).

Previous studies have compared airway inflammation in predefined patients with either asthma or COPD (11-16). The limitation of those studies is that they compared young patients having asthma with variable airflow obstruction with older COPD patients with fixed airflow obstruction. The results of those studies showed that, in asthma, the variable airflow obstruction is associated with a characteristic airway inflammation consisting of an increased number of T lymphocytes (predominantly CD4+) and eosinophils and an increased thickness of the reticular layer of the epithelial basement membrane (17). In contrast, in COPD the fixed airflow obstruction is associated with an airway inflammatory profile consisting mainly of an increased number of $\mathrm{T}$ lymphocytes (predominantly CD8+), macrophages, and neutrophils (18, 19).

Surprisingly, no previous study has investigated the characteristics of airway inflammation in patients of similar age and similar severity of fixed airflow obstruction but a different clinical history, i.e., a history of asthma or a history of COPD. In particular, the characteristics of airway inflammation in subjects with asthma who develop fixed airflow obstruction have not been investigated and are unknown. One could predict that in these patients airway inflammation would also change with the development of fixed airflow obstruction and become similar to the airway inflammation present in COPD. If so, asthma could become COPD not only functionally but also pathologically.

In this study we investigated whether subjects with fixed airflow obstruction have distinct airway inflammation depending on their history of asthma or COPD. We examined a group of consecutive patients presenting with fixed airflow obstruction, and analyzed lung function, exhaled nitric oxide (NO), high-resolution computed tomography (HRCT) scan of the chest, and airway pathology. We then compared $a$ posteriori those with a history of asthma with those with a history of COPD.

\section{METHODS}

We recruited all patients older than 50 years who presented at our clinic with fixed airflow obstruction from July 1998 through June 2000. Fixed airflow obstruction was defined as postbronchodilator $\mathrm{FEV}_{1} / \mathrm{FVC}$ less than $70 \%$ (6). From the 74 patients recruited, we report the results obtained in the 46 patients who agreed to participate in the study. 
TABLE 1. CHARACTERISTICS OF THE 46 PATIENTS WITH FIXED AIRFLOW OBSTRUCTION

\begin{tabular}{|c|c|c|c|}
\hline Characteristic/Pulmonary Function & $\begin{array}{l}\text { Fixed Airflow Obstruction } \\
\qquad(n=46)\end{array}$ & $\begin{array}{l}\text { History of COPD } \\
\qquad(n=27)\end{array}$ & $\begin{array}{l}\text { History of Asthma } \\
\qquad(n=19)\end{array}$ \\
\hline Age, yr & $65.3 \pm 1.1$ & $65.8 \pm 1.8$ & $64.3 \pm 1.9$ \\
\hline Sex, M/F & $30 / 16$ & $18 / 9$ & $12 / 7$ \\
\hline Smoking history (pack/years) & $\begin{array}{l}14 \text { nonsmokers, } 28 \text { ex- and } 4 \text { current } \\
\text { smokers }(35.8 \pm 4.7)\end{array}$ & $\begin{array}{l}23 \text { ex- and } 4 \text { current smokers } \\
(42.5 \pm 4.9)\end{array}$ & $\begin{array}{l}14 \text { nonsmokers }{ }^{\star * *}, 5 \text { exsmokers } \\
(0.9 \pm 0.4)\end{array}$ \\
\hline \multicolumn{4}{|l|}{ Treatment } \\
\hline Inhaled steroids, n (\%) & $37(80.4)$ & $21(77.7)$ & $16(84.5)$ \\
\hline \multicolumn{4}{|l|}{ Inhaled bronchodilators, $\mathrm{n}(\%)$} \\
\hline Short-acting & $40(86.9)$ & $22(81.4)$ & $18(94.7)$ \\
\hline Long-acting & $44(95.6)$ & $27(100)$ & $17(89.4)$ \\
\hline Theophylline & $5(10.8)$ & $2(7.4)$ & $3(15.7)$ \\
\hline Positive skin prick test, n (\%) & $19(41.3)$ & $3(11.1)$ & $16(84.2)^{\star \star \star}$ \\
\hline $\mathrm{FEV}_{1}, \mathrm{~L}$ & $1.62 \pm 0.06$ & $1.60 \pm 0.09$ & $1.65 \pm 0.11$ \\
\hline $\mathrm{FEV}_{1}, \%$ predicted & $56.4 \pm 1.8$ & $56.5 \pm 1.7$ & $56.3 \pm 3.1$ \\
\hline $\mathrm{FEV}_{1} / \mathrm{FVC}, \%$ & $51.9 \pm 1.1$ & $51.1 \pm 1.4$ & $53.1 \pm 2.1$ \\
\hline $\mathrm{FEV}_{1} / \mathrm{FVC}, \%$ predicted & $65.7 \pm 1.7$ & $64.6 \pm 2.0$ & $67.2 \pm 2.8$ \\
\hline $\mathrm{FEV}_{1}$ after bronchodilator, $\mathrm{L}$ & $1.79 \pm 0.10$ & $1.73 \pm 0.10$ & $1.87 \pm 0.12$ \\
\hline $\mathrm{FEV}_{1}$ after bronchodilator, \% predicted & $60.5 \pm 1.7$ & $59.3 \pm 1.9$ & $62.3 \pm 3.2$ \\
\hline $\mathrm{RV}, \mathrm{L}$ & $2.56 \pm 0.12$ & $2.82 \pm 0.17$ & $2.21 \pm 0.18^{*}$ \\
\hline RV, \% predicted & $121.4 \pm 5$ & $131.8 \pm 6.3$ & $106.6 \pm 6.9^{\star *}$ \\
\hline TLC, L & $6.86 \pm 0.32$ & $7.02 \pm 0.33$ & $6.64 \pm 0.58$ \\
\hline TLC, \% predicted & $106.4 \pm 3.5$ & $108.9 \pm 4.7$ & $102.8 \pm 5.2$ \\
\hline IC, L & $3.1 \pm 0.10$ & $3.0 \pm 0.12$ & $3.2 \pm 0.17$ \\
\hline $\mathrm{DL}_{\mathrm{CO}}, \mathrm{ml} / \mathrm{min} / \mathrm{mm} \mathrm{Hg}$ & $18.6 \pm 0.9$ & $15.0 \pm 0.3$ & $23.6 \pm 1.8^{* \star *}$ \\
\hline DLco, \% predicted & $71.2 \pm 4.6$ & $65.4 \pm 5.3$ & $85.0 \pm 6.4^{\star \star \star}$ \\
\hline $\mathrm{KcO}, \mathrm{ml} / \mathrm{min} / \mathrm{mm} \mathrm{Hg} / \mathrm{L}$ & $3.6 \pm 0.2$ & $3.1 \pm 0.2$ & $4.2 \pm 0.2^{* * *}$ \\
\hline Kco, \% predicted & $69.5 \pm 3.2$ & $60.0 \pm 3.9$ & $82.9 \pm 3.5^{\star \star \star}$ \\
\hline $\mathrm{Pa}_{\mathrm{O}_{2}}, \mathrm{~mm} \mathrm{Hg}$ & $74.7 \pm 1.3$ & $72.1 \pm 1.8$ & $78.5 \pm 1.8^{*}$ \\
\hline $\mathrm{Pa}_{\mathrm{CO}_{2}}, \mathrm{~mm} \mathrm{Hg}$ & $40.3 \pm 0.7$ & $40.3 \pm 0.8$ & $40.3 \pm 1.7$ \\
\hline $\mathrm{PH}$ & $7.40 \pm 0.06$ & $7.40 \pm 0.1$ & $7.39 \pm 0.05$ \\
\hline $\mathrm{PC}_{20} \mathrm{FEV}_{1}, \mathrm{mg} / \mathrm{ml}$ geometric mean (SD) & $2.03(3.2)$ & $2.81(3.1)$ & $1.17(3.3)$ \\
\hline$\Delta \mathrm{FEV}_{1}$ after bronchodilator, $\mathrm{ml}$ & $176 \pm 23.7$ & $122.7 \pm 17.2$ & $251.7 \pm 44.7^{*}$ \\
\hline$\Delta \mathrm{FEV}_{1}$ after bronchodilator, $\%$ predicted & $6.23 \pm 1.1$ & $4.5 \pm 0.8$ & $8.7 \pm 2.4^{\star *}$ \\
\hline$\Delta \mathrm{FEV}_{1}$ after corticosteroids, $\mathrm{ml}$ & $191.1 \pm 48.3$ & $100.4 \pm 45.3$ & $320 \pm 70.4^{*}$ \\
\hline$\Delta \mathrm{FEV}_{1}$ after corticosteroids, $\%$ predicted & $7.1 \pm 1.77$ & $3.6 \pm 1.5$ & $12.1 \pm 2.4^{* *}$ \\
\hline HRCT emphysema score ${ }^{\dagger}$ & $2.5 \pm 0.5$ & $3.6 \pm 0.7$ & $0.6 \pm 0.3^{*}$ \\
\hline
\end{tabular}

Definition of abbreviations: $\mathrm{COPD}=$ chronic obstructive pulmonary disease; $\mathrm{DL}_{\mathrm{CO}}=$ transfer factor of the lung for carbon monoxide; $\mathrm{F}=$ female; $\mathrm{HRCT}=$ high-

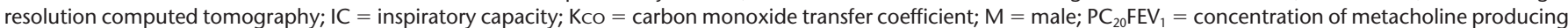
a $20 \%$ fall in $\mathrm{FEV}_{1}$; RV = residual volume; TLC = total lung capacity.

Significantly different from patients with a history of COPD: ${ }^{*} p<0.05,{ }^{* *} p<0.01,{ }^{* * *} p<0.001$.

${ }^{\dagger}$ Patients with a history of asthma, $\mathrm{n}=10$; patients with a history of COPD, $\mathrm{n}=21 . \Delta=$ change.

Each patient was characterized by medical history and physical examination. Of the 46 patients studied, 19 had a history of asthma and 27 had a history of COPD. Those with a history of asthma had previous recurrent episodes of wheezing, breathlessness, chest tightness, and/or cough and previously documented variable airflow obstruction to inhaled albuterol; they were either lifelong nonsmokers or exsmokers for more than 12 months, with less than 5 cumulative pack-years. Patients with a history of COPD had a history of chronic respiratory symptoms, i.e., cough and sputum and/or breathlessness and only occasional wheezing; they were all smokers or exsmokers (two lifelong nonsmokers were excluded) with more than 20 pack-years and a documented absence of a history of variable airflow obstruction. We excluded patients who had an exacerbation requiring pharmacologic treatment in the 6 months before the study. The number and severity of exacerbations before the 6 months preceding the study were not recorded. All subjects were allowed to continue ongoing medication, with the exclusion of oral steroids (Table 1).

Each patient performed pulmonary function tests, including reversibility to inhaled bronchodilator $(200 \mu \mathrm{g}$ albuterol) and to corticosteroids (15-day course with oral prednisone, $50 \mathrm{mg}$ /day); airway responsiveness to methacholine; tests for atopic status and exhaled NO; induced sputum; arterial blood gases; and white blood cell count (20). In addition, 13 of the 19 patients with a history of asthma and 15 of the 27 patients with a history of COPD underwent bronchoscopy, bronchoalveolar lavage, and bronchial biopsy according to previously described methods $(12,20,21)$. Biopsy specimens suitable for morphometric analysis were obtained in 10 patients with a history of asthma and 11 patients with a history of COPD. Finally, a subgroup of 31 patients - 10 with a history of asthma and 21 with a history of COPDunderwent HRCT of the chest for radiologic assessment of emphysema, using a previously described scoring system (22). Additional methodologic details are provided in an online supplement.

\section{Statistical Analysis}

The statistical analysis was performed according to the previously reported methodology briefly described in the online supplement $(23,24)$.

Receiver operating characteristic (ROC) curve analysis was performed for all the functional/pathologic parameters that were thought to define the capability/power of each variable (predictive value) to recognize patients with a history of asthma within our study population. The area under the ROC curves was determined, and a value above 0.80 was considered a good discrimination (25). ROC curve analysis also allowed (sensitivity versus 1 minus specificity) selection of the best cutoff point of each variable for discriminating between the two groups.

\section{RESULTS}

\section{Pulmonary Function and HRCT}

The characteristics of the study subjects are reported in Table 1. On the whole, the subjects were elderly, with moderate to severe fixed airflow obstruction. Age, $\mathrm{FEV}_{1}$ and $\mathrm{FEV}_{1} / \mathrm{FVC}, \mathrm{PC}_{20} \mathrm{FEV}_{1}$, and total lung capacity were no different between the 19 patients with asthma and the 27 patients with COPD. Patients with a 


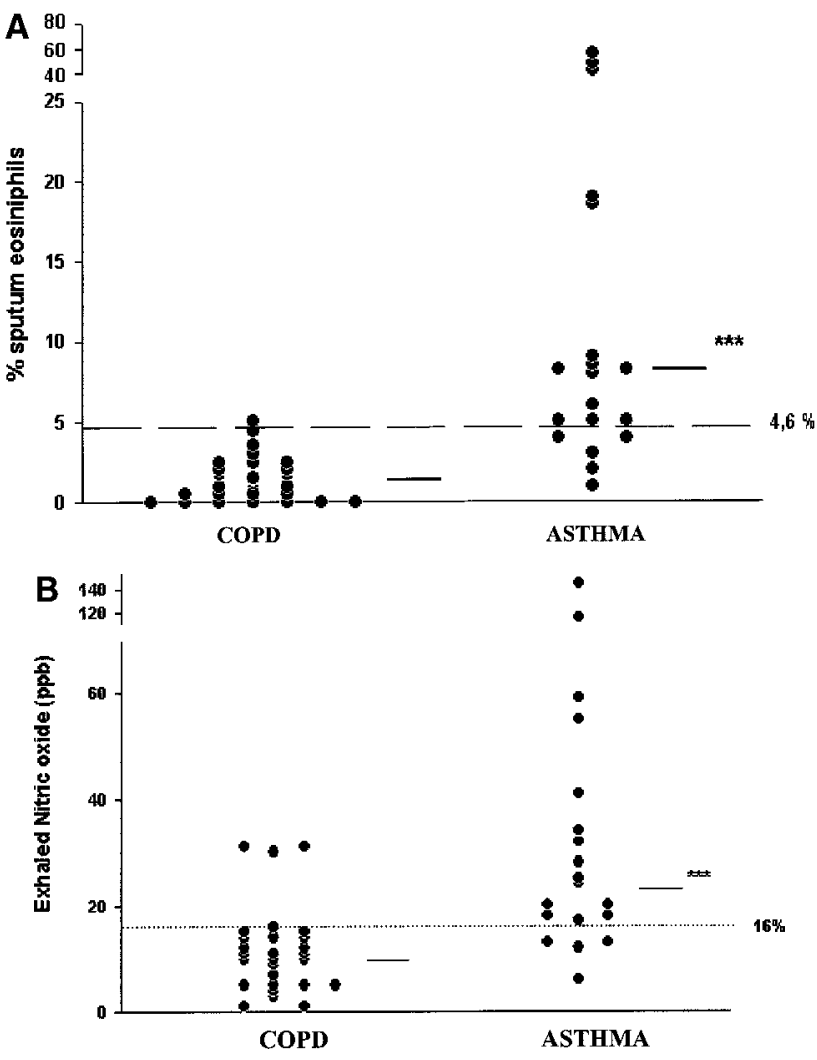

Figure 1. Percent sputum eosinophils (upper panel) and concentration of exhaled NO (lower panel) in patients with fixed airflow obstruction and a history of either asthma or COPD. The horizontal solid bars indicate the median value for each group. The best cutoff points to discriminate between the two groups are $4.6 \%$ sputum eosinophils (upper panel) and $16 \mathrm{ppb}$ exhaled NO (lower panel). Asterisks indicate a significant difference $(p<0.01)$ between patients with a history of asthma and patients with a history of COPD.

history of asthma had lower residual volume, higher diffusing capacity and oxygen tension in arterial blood, and an increased response to inhaled albuterol and steroids (Table 1).

A subgroup of 31 patients -10 with a history of asthma and 21 with a history of COPD - underwent an HRCT scan of the chest. Patients with a history of asthma had a lower HRCT scan emphysema score than did patients with a history of COPD $(0.6 \pm 0.3$ versus $3.6 \pm 0.7 ; \mathrm{p}=0.01)$.
COPD
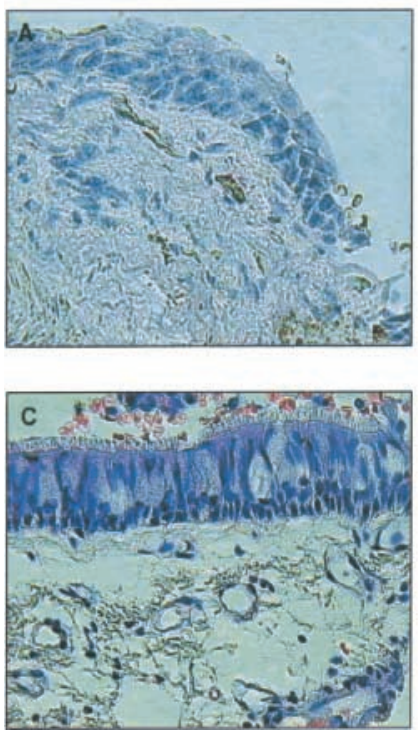

Asthma
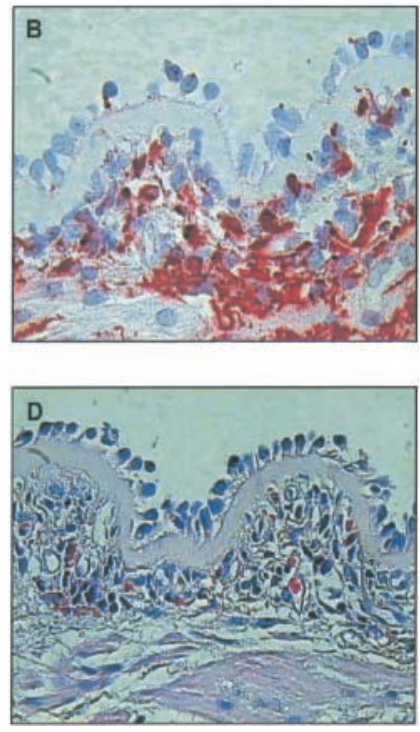

Figure 2. $(A)$ and $(B)$ : Photomicrographs showing bronchial biopsy specimens immunostained with anti-EG-2 (eosinophil cationic protein) from a patient with fixed airflow obstruction and a history of COPD $(A)$ and from a patient with fixed airflow obstruction and a history of asthma $(B)$. The two patients had a similar degree of fixed airflow obstruction. In $(B)$, there is prominent eosinophilia beneath the destroyed epithelium that is not present in $(A)$. (C) and $(D)$ : Photomicrographs showing bronchial biopsy specimens stained with H\&E from a patient with fixed airflow obstruction and a history of COPD (C) and from a patient with fixed airflow obstruction and a history of asthma $(D)$. The two patients had a similar degree of fixed airflow obstruction. In $(D)$, there is a thicker reticular layer of the epithelial basement membrane compared with (C).

\section{Inflammatory Markers}

Compared with the patients with a history of COPD, patients with a history of asthma had more eosinophils in peripheral blood (5.4\% [3.6-6.4\%] versus 2.9\% [2.1-3.5\%]; p < 0.01), sputum $(8.5 \%$ [1.8-43.5\%] versus $1.25 \%$ [0.5-3.2\%]; p $<0.01)$ (Figure 1A), bronchoalveolar lavage fluid (3.9\% [1-7.5\%] versus $0 \%[0-0.5 \%] ; \mathrm{p}<0.05)$, and airway mucosa $\left[50\right.$ cells $/ \mathrm{mm}^{2}[10-280$ cells $\left./ \mathrm{mm}^{2}\right]$ versus 5 cells $/ \mathrm{mm}^{2}\left[2.3-33\right.$ cells $\left.\left./ \mathrm{mm}^{2}\right] ; \mathrm{p}<0.01\right]$ (Table 2 , Figure $2 \mathrm{~A}, 2 \mathrm{~B})$ and had fewer neutrophils in sputum $(48 \%$ [28-64.5\%] versus 79.2\% [53-90\%]; p < 0.05) (Table 3) and bronchoalveolar lavage fluid $(2.5 \%[1-6 \%]$ versus $12.5 \%$ [7.5-

TABLE 2. INFLAMMATORY CELLS IN THE LAMINA PROPRIA OF THE AIRWAY WALL IN PATIENTS WITH FIXED AIRFLOW OBSTRUCTION

\begin{tabular}{lccc}
\hline Cells $\left(\right.$ cells $\left./ \mathrm{mm}^{2}\right)$ & $\begin{array}{c}\text { Fixed Airflow Obstruction } \\
(n=21)\end{array}$ & $\begin{array}{c}\text { History of COPD } \\
(n=11)\end{array}$ & $\begin{array}{c}\text { History of Asthma } \\
(n=10)\end{array}$ \\
\hline Macrophages & $91.3(47-102)$ & $99.4(65-105.6)$ & $86(41-97.7)$ \\
Neutrophils & $109.5(71-180)$ & $88.5(43-156)$ & $157(99-183)$ \\
Eosinophils & $30(5-57.5)$ & $5(2.3-33)$ & $50(10-280)^{\star *}$ \\
Mast cells & $45(13.5-70)$ & $40(18.7-65)$ & $53(9.2-120)$ \\
CD4+ & $142(65-210)$ & $109(18-138.2)$ & $218(110.7-372.2)^{*}$ \\
CD8+ & $45(25.2-102)$ & $72.5(36.5-145)$ & $40(15.2-71.5)$ \\
CD4+/CD8+ & $2(0.97-7.75)$ & $1.2(0.27-3.15)$ & $7(2-21)^{*}$
\end{tabular}

Definition of abbreviation: COPD = chronic obstructive pulmonary disease.

Data are expressed as the medians with interquartile range shown in parentheses. Significantly different from the values for COPD patients: ${ }^{*} p<0.05,{ }^{* *} p<0.01$. 
TABLE 3. DIFFERENTIAL SPUTUM CELL COUNTS IN PATIENTS WITH FIXED AIRFLOW OBSTRUCTION

\begin{tabular}{lccc}
\hline Cells $(\%)$ & $\begin{array}{c}\text { Fixed Airflow Obstruction } \\
(n=46)\end{array}$ & $\begin{array}{c}\text { History of COPD } \\
(n=27)\end{array}$ & $\begin{array}{c}\text { History of Asthma } \\
(n=19)\end{array}$ \\
\hline Macrophages & $22(8.2-40.2)$ & $19.7(7.5-38.5)$ & $26.4(14-40.2)$ \\
Neutrophils & $64.5(43.5-85.2)$ & $79.2(53-90)$ & $48(28-64.5)^{*}$ \\
Eosinophils & $2.5(0.5-6.7)$ & $1.25(0.5-3.2)$ & $8.5(1.8-43.5)^{\star *}$ \\
Lymphocytes & $0.5(0-1)$ & $0.5(0-0.75)$ & $0.75(0-1.12)$ \\
\hline
\end{tabular}

Definition of abbreviation: COPD = chronic obstructive pulmonary disease.

Data are expressed as the medians with interquartile range shown in parentheses. Significantly different from the values for patients with history of COPD: ${ }^{*} p<0.05,{ }^{* *} p<0.01$.

$40 \%$ ]; $\mathrm{p}<0.01)$. Patients with a history of asthma had more bronchoalveolar lymphocytes $(6.5 \%$ [3-11.5\%] versus $1.5 \%$ [1$4 \%] ; \mathrm{p}<0.05$ ) and more CD4+ cells (Table 2), a higher CD $4+/$ $\mathrm{CD} 8+$ ratio (Table 2), and a thicker reticular layer of the basement membrane $(8.35 \mu \mathrm{m}$ [6.6-9.7 $\mu \mathrm{m}$ ] versus $5 \mu \mathrm{m}$ [4.2-6.2 $\mu \mathrm{m}] ; \mathrm{p}<0.01$ ) (Figure 2C, 2D) in bronchial biopsy specimens. Finally, patients with a history of asthma had a higher level of exhaled NO $(37.5 \pm 9.2 \mathrm{ppb}$ versus $11.1 \pm 1.7 \mathrm{ppb} ; \mathrm{p}<0.01)$ (Figure 1B).

\section{ROC Curve Analysis}

None of the functional parameters were able to recognize patients with a history of asthma among subjects with fixed airflow obstruction due to asthma or COPD. Indeed, although the variables were significantly different between the two groups (Table 1$)$, the values of the area under the ROC curves $(0.71$ for reversibility to bronchodilators, 0.73 for reversibility to steroids, 0.66 for carbon monoxide transfer coefficient (KCO), 0.63 for residual volume, and 0.61 for $\mathrm{Pa}_{\mathrm{O}_{2}}$ ) were below 0.80 , suggesting that these parameters are poor predictors of the diagnosis of history of asthma. In contrast, both the percentage of sputum and bronchoalveolar lavage eosinophils and the NO level were good predictors of a history of asthma. The area under the ROC curve was 0.95 for the percentage of eosinophils in bronchoalveolar lavage fluid, 0.88 for the percentage of eosinophils in sputum, and 0.86 for exhaled NO. For bronchoalveolar lavage eosinophils, values higher than or equal to $0.75 \%$ (best cutoff point with a sensitivity of 0.88 and a specificity of 0.91 ) predicted a history of asthma, whereas values lower than $0.75 \%$ predicted a history of COPD among subjects with fixed airflow obstruction. Similarly, for sputum eosinophils, the best cutoff point was $4.6 \%$ (with a sensitivity of 0.96 and a specificity of 0.74 ), indicating that values higher than or equal to $4.6 \%$ predicted a history of asthma, whereas values lower than $4.6 \%$ predicted a history of COPD among subjects with fixed airflow obstruction. For exhaled NO, the best cutoff point was $16 \mathrm{ppb}$, which had a sensitivity of 0.91 and a specificity of 0.77 ; values higher than $16 \mathrm{ppb}$ predicted a history of asthma, whereas values lower than $16 \mathrm{ppb}$ predicted a history of COPD among subjects with fixed airflow obstruction.

\section{DISCUSSION}

In this study we showed that, within a group of patients with fixed airflow obstruction, those with a history of asthma have distinct airway inflammation as compared with those with a history of smoking-induced COPD. This finding suggests that asthmatic airway inflammation does not change with the development of fixed airflow obstruction and thus does not become similar to the airway inflammation characteristic of COPD.

Thus, even when they develop fixed airflow obstruction, patients with a history of asthma have the same airway inflamma- tory changes that are present in patients with asthma with variable airflow obstruction, in terms of both cellular infiltrates and increased thickness of the reticular layer of the basement membrane. Our results therefore indicate that, even when fixed airflow obstruction is present, asthma should be diagnosed as asthma and not as COPD.

\section{Pathology}

Previous studies, including our own, have compared airway inflammation in asthma and COPD (11-14). Indeed, those studies showed almost the same differences that we report in the present study, suggesting that our results were predictable. The major limitation of all those studies is that they compared young patients with asthma who had variable airflow obstruction with older COPD patients who had fixed airflow obstruction; thus, they did not address the issue of whether the pathology of asthma changes with the development of fixed airflow obstruction and becomes similar to that characteristic of COPD. Indeed, previous studies have included patients with asthma of various degrees of severity, but (1) they were younger than the patients included in our study and/or had milder fixed airflow obstruction $(11,12)$, and/or (2) they were steroid-dependent $(26,27)$, in which case systemic steroids may have influenced the pathology (28). Also, the patients examined were clearly identified as suffering from asthma, and the differential diagnosis with COPD was not even considered. By contrast, in our study the patients with asthma that we recruited were actually identified as having COPD because they presented with fixed airflow obstruction.

The unique feature of our study is that we investigated the characteristics of airway inflammation in patients of similar age and a similar degree of fixed airflow obstruction but with a different clinical history, i.e., asthma or COPD. Thus, we studied a unique group of patients with fixed airflow obstruction and a history of asthma, a group that had never been properly examined and described before and that had never been compared with patients with COPD with similar characteristics.

\section{Lung Function and Imaging}

In one study, clinical features, lung function, and thoracic imaging, but not inflammatory characteristics, were compared in patients of similar age and a similar degree of fixed airflow obstruction who had asthma or COPD (29). It was shown that lung function characteristics and emphysematous changes on HRCT scan were different in the two groups of subjects. The results of our study confirm and extend those results because we showed that reversibility of airflow obstruction to steroids, residual volume, and arterial blood gases are also different between the two groups. The higher diffusing capacity and $\mathrm{Pa}_{\mathrm{O}_{2}}$ and the lower residual volume and HRCT emphysema score observed in subjects with fixed airflow obstruction due to asthma observed in both studies suggest that lung parenchyma is less 
involved in asthma. By contrast, the lower diffusing capacity and $\mathrm{Pa}_{\mathrm{O}_{2}}$, the higher residual volume, and the higher HRCT emphysema score in patients with fixed airflow obstruction due to COPD suggest that parenchymal destruction, i.e., emphysema, is present in COPD.

By examining a sufficiently large number of subjects, we were able to show that differences in lung function tests, although statistically significant, cannot be used clinically to separate the two groups of subjects because of the large overlap (see the analysis of the ROC curves), whereas both bronchoalveolar lavage and sputum eosinophilia and exhaled NO can indeed separate the two groups.

\section{Relationship Between Pathology and Lung Function}

The relationship between airway inflammation and airflow obstruction is poorly understood both in asthma and in COPD. The increased number of a certain cell type, e.g., eosinophils and CD4+ lymphocytes in asthma or neutrophils and CD8+ lymphocytes in COPD, is unlikely to be the major determinant of airflow obstruction, but it may be a marker of two different inflammatory cascades for two diseases, asthma and COPD, that result in the same functional abnormality, i.e., fixed airflow obstruction.

Structural changes of the airways (rather than changes in lung parenchyma) that may narrow and obliterate the airway lumen seem more likely to be the major determinant of airflow obstruction in asthma, even though an unsuspected and unexplained reduction of elastic recoil was recently reported in severe asthma (30). The infiltration of the airways with eosinophils and CD4+ lymphocytes is accompanied by airway remodeling characterized by vasodilatation, microvascular leakage, excessive formation of mucus and exudates, epithelial disruption and increased numbers of epithelial goblet cells, smooth muscle hypertrophy, and, particularly, deposition of interstitial collagens beneath the epithelium, all changes that may play a role in fixed airflow obstruction (17). In this scenario, the CD4+ Th2 lymphocytes may have important functions in directing and maintaining this specific asthmatic airway inflammatory cascade $(15,17)$.

In contrast with asthma, structural changes of both the airways (particularly peripheral airways) and the lung parenchyma seem to contribute to airflow obstruction in $\operatorname{COPD}(31,32)$. Infiltration of the airways with neutrophils and CD8+ lymphocytes in COPD is also associated with remodeling of the airways, characterized by goblet cell metaplasia and mucous plugging, smooth muscle hypertrophy, and airway wall fibrosis and distortion that may narrow and obliterate the airway lumen (16). In addition, destruction of lung parenchyma, i.e., emphysema, contributes to airflow obstruction by destruction of alveolar support to peripheral airways, loss of elastic recoil in the parenchyma supporting the airways, and decreased elastic force available to drive flow out of the lung (32). In this scenario, the CD8+ Th1 lymphocytes may have important functions in directing and maintaining the airway and lung inflammatory cascade present in COPD (33).

Our observation of a lack of neutrophilia in patients with asthma may appear to be in conflict with the findings of Wenzel and coworkers, who showed a prominent neutrophilia in bronchial biopsy specimens of patients with asthma who had a similar degree of airflow obstruction $(26,27)$. However, at variance with our study, those patients were steroid-dependent, requiring high doses of oral/inhaled glucocorticosteroids for many years, indicating a more severe disease. It is possible that the distinct airway inflammation observed in asthma and COPD in our study may disappear as asthma and COPD become more severe; not only severe asthma $(26,27,34,35)$ but also severe COPD (36) are associated with marked airway neutrophilia. Also, ongoing treatment, particularly with inhaled steroids, that was allowed in the subjects we examined may have had a differential effect in patients with a history of asthma or COPD; however, this is unlikely, because patients with asthma were only on inhaled steroids (and not on systemic steroids) and had eosinophilia in bronchial biopsy specimens, bronchoalveolar lavage, and sputum. This is in keeping with the previous report of sputum eosinophilia in patients with severe persistent asthma who were receiving inhaled steroids (28). Interestingly, it was recently reported that sputum eosinophilia is one of the most important determinants of the development of persistent airflow obstruction in severe asthma (5).

\section{Site of Inflammation and Airflow Obstruction}

One limitation of our study is that none of the techniques we used to characterize airway inflammation is specific for the peripheral airways. However, even if there is no doubt that the main site of airflow obstruction in COPD is the peripheral airways, there are now several studies showing that in addition to peripheral airways (24), central airways are also inflamed and involved in this disease $(19,37)$. Regarding asthma, Carroll's group has elegantly shown that both central and peripheral airways are inflamed in subjects having asthma with a wide range of disease severity $(38,39)$. Thus, according to these and other studies, both central and peripheral airways are involved in the pathology of asthma and COPD $(15,40)$. Surgical tissues obtained from patients undergoing lobectomy for lung cancer (tissues difficult to obtain in patients with asthma) and autopsy tissues are the only specimens that allow the proper examination of peripheral airways in humans. Transbronchial biopsies have also been used (41-43), but the proportion of useful samples that can be properly analyzed is limited, the morphometric analysis of tissue is difficult, and the biopsy technique is associated with significant risks for the patients. Because we were interested in investigating airway pathology in living patients, we thought that bronchial biopsies, bronchoalveolar lavage, and sputum were the best tools for the main purpose of our study.

\section{Predictive Value of Markers of Inflammation and Lung Function Parameters}

The differential diagnosis between fixed airflow obstruction due to asthma or COPD is important in clinical practice because the prognosis and the response to treatment of the two diseases are different $(8,9)$. The results of our study show that measurement of lung volumes, responsiveness to bronchodilators or steroids, and even diffusing capacity overlap considerably, making these tests of little use for distinguishing the two groups. Airway hyperresponsiveness to methacholine was also not significantly different between the two groups, confirming that, once fixed airflow obstruction develops, measurement of airway responsiveness to methacholine is not useful for distinguishing asthma from COPD (44-47). Interestingly, the degree of airway hyperresponsiveness in patients with a history of asthma was similar to that reported by Boulet and coworkers in a group of patients with asthma with fixed airflow obstruction (48).

Sputum and bronchoalveolar lavage eosinophilia and exhaled NO, which are well-established markers of airway inflammation in asthma (49), are also the most reliable objective measurements that help to distinguish asthma from COPD once fixed airflow obstruction has developed. These results suggest that, in particular, the noninvasive measurements of eosinophils in sputum and exhaled NO might be clinically useful in assessing the relative contributions of asthma and COPD in patients without a clear clinical history or in those with multiple risk factors (e.g., individ- 
uals with asthma who smoke or patients with COPD who develop recurrent symptoms) (50). In the differential diagnosis, one should also consider other patients with similar characteristics, i.e., (1) COPD occurring in nonsmokers (51) and (2) obstructive eosinophilic bronchitis, a syndrome that has been described in smokers with no history of asthma but with sputum eosinophilia $(52,53)$. Using the discriminating point of $4.6 \%$ sputum eosinophils identified in our study, we found that only 1 of the 27 patients with COPD had sputum eosinophilia. Using the previously proposed discriminating point of $3 \%$ sputum eosinophils (52), 4 of the 27 patients with COPD had eosinophilic bronchitis $(14.8 \%)$, confirming that eosinophilia may occur in only a minority of patients with COPD. Because these patients with COPD respond to steroids as asthma patients do, they should be properly identified and treated (53).

\section{Conclusions}

The results of our study show that, despite similar fixed airflow obstruction, subjects with a history of asthma have distinct functional and pathologic characteristics compared with subjects with a history of COPD. These differences may explain the better prognosis (8) and the better response to steroids (9) described in patients with fixed airflow obstruction due to asthma compared with patients with fixed airflow obstruction due to COPD.

The results of our study suggest that, in clinical practice, patients with fixed airflow obstruction due to asthma should not be grouped under the general heading of COPD. Rather, they should be properly identified and treated $(6,54)$.

Acknowledgment: The authors are indebted to Ms. Mimi Zeiger and Mary McKenney for their careful editorial review of the manuscript and correspondence, to Dr. Elena Forini for statistical assistance, and to Dr. Elisa Veratelli for the scientific secretarial assistance.

\section{References}

1. BTS guidelines for the management of chronic obstructive pulmonary disease. The COPD Guidelines Group of the Standards of Care Committee of the BTS (British Thoracic Society). Thorax 1997;52:S1-S28.

2. Celli BR, Snider GL, Heffner J, Tiep B, Ziment I, Make B, Braman S, Olsen G, Philips Y. Standards for the diagnosis and care of patients with chronic obstructive pulmonary disease: American Thoracic Society. Am J Respir Crit Care Med 1995;152:S77-S121.

3. Fletcher C, Peto R. The natural history of chronic airflow obstruction. BMJ 1977;1:1645-1648.

4. Lange P, Parner J, Vestbo J, Schnohr P, Jensen G. A 15-year follow-up study of ventilatory function in adults with asthma. N Engl J Med 1998; 339:1194-1200.

5. ten Brinke A, Zwinderman AH, Sterk PJ, Rabe KF, Bel EH. Factors associated with persistent airflow limitation in severe asthma. Am J Respir Crit Care Med 2001;164:744-748.

6. Pauwels RA, Buist AS, Calverley PM, Jenkins CR, Hurd SS. Global strategy for the diagnosis, management, and prevention of chronic obstructive pulmonary disease: NHLBI/WHO global initiative for chronic obstructive lung disease (GOLD) workshop summary. Am J Respir Crit Care Med 2001;163:1256-1276.

7. McIvor RA, Tashkin DP. Underdiagnosis of chronic obstructive pulmonary disease: a rationale for spirometry as a screening tool. Can Respir J 2001;8:153-158.

8. Burrows B, Bloom JW, Traver GA, Cline MG. The course and prognosis of different forms of chronic airways obstruction in a sample from the general population. N Engl J Med 1987;317:1309-1314.

9. Kerstjens HA, Brand PL, Hughes MD, Robinson NJ, Postma DS, Sluiter HJ, Bleecker ER, Dekhuijzen PN, de Jong PM, Mengelers HJ, et al. A comparison of bronchodilator therapy with or without inhaled corticosteroid therapy for obstructive airways disease: Dutch Chronic Non-Specific Lung Disease Study Group. N Engl J Med 1992;327:14131419.

10. Mannino DM, Gagnon RC, Petty TL, Lydick E. Obstructive lung disease and low lung function in adults in the United States: data from the National Health and Nutrition Examination Survey, 1988-1994. Arch Intern Med 2000;160:1683-1689.

11. Ollerenshaw SL, Woolcock AJ. Characteristics of the inflammation in biopsies from large airways of subjects with asthma and subjects with chronic airflow limitation. Am Rev Respir Dis 1992;145:922-927.

12. Saetta M, Di Stefano A, Maestrelli P, Turato G, Mapp CE, Pieno M, Zanguochi G, Del Prete G, Fabbri LM. Airway eosinophilia and expression of interleukin-5 protein in asthma and in exacerbations of chronic bronchitis. Clin Exp Allergy 1996;26:766-774.

13. Keatings VM, Jatakanon A, Worsdell YM, Barnes PJ. Effects of inhaled and oral glucocorticoids on inflammatory indices in asthma and COPD. Am J Respir Crit Care Med 1997;155:542-548.

14. Vignola AM, Chanez P, Chiappara G, Siena L, Merendino A, Reina C, Gagliardo R, Profita M, Bousquet J, Bonsignore G. Evaluation of apoptosis of eosinophils, macrophages, and T lymphocytes in mucosal biopsy specimens of patients with asthma and chronic bronchitis. $J$ Allergy Clin Immunol 1999;103:563-573.

15. Jeffery PK. Comparison of the structural and inflammatory features of COPD and asthma: Giles F. Filley Lecture. Chest 2000;117:251S-260S.

16. Jeffery PK. Remodeling in asthma and chronic obstructive lung disease. Am J Respir Crit Care Med 2001;164:S28-S38.

17. Bousquet J, Jeffery PK, Busse WW, Johnson M, Vignola AM. Asthma From bronchoconstriction to airways inflammation and remodeling. Am J Respir Crit Care Med 2000;161:1720-1745.

18. Barnes PJ. Chronic obstructive pulmonary disease. N Engl J Med 2000; 343:269-280.

19. Saetta M, Turato G, Maestrelli P, Mapp CE, Fabbri LM. Cellular and structural bases of chronic obstructive pulmonary disease. Am J Respir Crit Care Med 2001;163:1304-1309.

20. Papi A, Romagnoli M, Baraldo S, Braccioni F, Guzzinati I, Saetta M, Ciaccia A, Fabbri LM. Partial reversibility of airflow limitation and increased exhaled NO and sputum eosinophilia in chronic obstructive pulmonary disease. Am J Respir Crit Care Med 2000;162:1773-1777.

21. Rogge L, Papi A, Presky DH, Biffi M, Minetti LJ, Miotto D, Agostini C, Semenzato G, Fabbri LM, Sinigaglia F. Antibodies to the IL-12 receptor beta 2 chain mark human Th1 but not Th2 cells in vitro and in vivo. J Immunol 1999;162:3926-3932.

22. Paganin F, Seneterre E, Chanez P, Daures JP, Bruel JM, Michel FB, Bousquet J. Computed tomography of the lungs in asthma: influence of disease severity and etiology. Am J Respir Crit Care Med 1996;153: 110-114.

23. Panina-Bordignon P, Papi A, Mariani M, Di Lucia P, Casoni G, Bellettato C, Buonsanti C, Miotto D, Mapp C, Villa A, et al. The C-C chemokine receptors CCR4 and CCR8 identify airway $\mathrm{T}$ cells of allergen-challenged atopic asthmatics. J Clin Invest 2001;107:1357-1364.

24. Saetta M, Di Stefano A, Turato G, Facchini FM, Corbino L, Mapp CE, Maestrelli P, Ciaccia A, Fabbri LM. CD8+ T-lymphocytes in peripheral airways of smokers with chronic obstructive pulmonary disease. Am J Respir Crit Care Med 1998;157:822-826.

25. Hanley JA, McNeil BJ. The meaning and use of the area under a receiver operating characteristic (ROC) curve. Radiology 1982;143:29-36.

26. Wenzel SE, Schwartz LB, Langmack EL, Halliday JL, Trudeau JB, Gibbs RL, Chu HW. Evidence that severe asthma can be divided pathologically into two inflammatory subtypes with distinct physiologic and clinical characteristics. Am J Respir Crit Care Med 1999;160:1001-1008.

27. Wenzel SE, Szefler SJ, Leung DY, Sloan SI, Rex MD, Martin RJ. Bronchoscopic evaluation of severe asthma: persistent inflammation associated with high dose glucocorticoids. Am J Respir Crit Care Med 1997; 156:737-743.

28. Louis R, Lau LC, Bron AO, Roldaan AC, Radermecker M, Djukanovic $\mathrm{R}$. The relationship between airways inflammation and asthma severity. Am J Respir Crit Care Med 2000;161:9-16.

29. Boulet LP, Turcotte H, Hudon C, Carrier G, Maltais F. Clinical, physiological and radiological features of asthma with incomplete reversibility of airflow obstruction compared with those of COPD. Can Respir J 1998;5:270-277.

30. Gelb AF, Licuanan J, Shinar CM, Zamel N. Unsuspected loss of lung elastic recoil in chronic persistent asthma. Chest 2002;121:715-721.

31. Pride NB. Pulmonary physiology. In: Barnes PJ, Drazen JM, Rennard S, Thomson NC, editors. ASTHMA and COPD: basic mechanisms and clinical management. San Diego, CA: Academic Press; 2002. p. 43-56.

32. Hogg JC. Airway pathology. In: Barnes PJ, Drazen JM, Rennard S, Thomson NC, editors. ASTHMA and COPD: basic mechanisms and clinical management. San Diego, CA: Academic Press; 2002. p. 57-67.

33. Saetta M, Mariani M, Panina-Bordignon P, Turato G, Buonsanti C, Baraldo S, Bellettato CM, Papi A, Corbetta L, Zuin R, et al. Increased expression of the chemokine receptor CXCR3 and its ligand CXCL10 in peripheral airways of smokers with chronic obstructive pulmonary disease. Am J Respir Crit Care Med 2002;165:1404-1409. 
34. Lamblin C, Gosset P, Tillie-Leblond I, Saulnier F, Marquette CH, Wallaert B, Tonnel AB. Bronchial neutrophilia in patients with noninfectious status asthmaticus. Am J Respir Crit Care Med 1998;157:394-402.

35. Jatakanon A, Uasuf C, Maziak W, Lim S, Chung KF, Barnes PJ. Neutrophilic inflammation in severe persistent asthma. Am J Respir Crit Care Med 1999;160:1532-1539.

36. Di Stefano A, Capelli A, Lusuardi M, Balbo P, Vecchio C, Maestrelli P, Mapp CE, Fabbri LM, Donner CF, Saetta M. Severity of airflow limitation is associated with severity of airway inflammation in smokers. Am J Respir Crit Care Med 1998;158:1277-1285.

37. O'Shaughnessy TC, Ansari TW, Barnes NC, Jeffery PK. Inflammation in bronchial biopsies of subjects with chronic bronchitis: inverse relationship of CD8+ T lymphocytes with FEV1. Am J Respir Crit Care Med 1997;155:852-857.

38. Carroll N, Elliot J, Morton A, James A. The structure of large and small airways in nonfatal and fatal asthma. Am Rev Respir Dis 1993;147:405410.

39. Carroll N, Cooke C, James A. The distribution of eosinophils and lymphocytes in the large and small airways of asthmatics. Eur Respir J 1997:10:292-300.

40. Howarth PH. Small airways and asthma: an important therapeutic target? Am J Respir Crit Care Med 1998;157:S173.

41. Boulet LP. Transbronchial biopsy as a tool to evaluate small-airways disease in asthma. Pros. Eur Respir J 2002:20:247-248.

42. Balzar S, Wenzel SE, Chu HW. Transbronchial biopsy as a tool to evaluate small airways in asthma. Eur Respir J 2002;20:254-259.

43. James A, Carroll N. Transbronchial biopsy as a tool to evaluate smallairways disease in asthma. Cons. Eur Respir J 2002;20:249-251.

44. Hargreave FE, O'Byrne PM, Ramsdale EH. Mediators, airway responsiveness, and asthma. J Allergy Clin Immunol 1985;76:272-276.

45. Tashkin DP, Altose MD, Bleecker ER, Connett JE, Kanner RE, Lee WW, Wise R. The lung health study: airway responsiveness to inhaled methacholine in smokers with mild to moderate airflow limitation:
The Lung Health Study Research Group. Am Rev Respir Dis 1992;145: 301-310.

46. Kanner RE, Connett JE, Altose MD, Buist AS, Lee WW, Tashkin DP, Wise RA. Gender difference in airway hyperresponsiveness in smokers with mild COPD: The Lung Health Study. Am J Respir Crit Care Med 1994;150:956-961

47. Crapo RO, Casaburi R, Coates AL, Enright PL, Hankinson JL, Irvin CG, MacIntyre NR, McKay RT, Wanger JS, Anderson SD, et al. Guidelines for methacholine and exercise challenge testing:1999. Am J Respir Crit Care Med 2000;161:309-329.

48. Boulet L, Belanger M, Carrier G. Airway responsiveness and bronchialwall thickness in asthma with or without fixed airflow obstruction. Am J Respir Crit Care Med 1995;152:865-871.

49. Gibson PG, Henry RL, Thomas P. Noninvasive assessment of airway inflammation in children: induced sputum, exhaled nitric oxide, and breath condensate. Eur Respir J 2000;16:1008-1015.

50. Kharitonov SA, Barnes PJ. Clinical aspects of exhaled nitric oxide. Eur Respir J 2000;16:781-792.

51. Birring SS, Brightling CE, Bradding P, Entwisle JJ, Vara DD, Grigg J, Wardlaw AJ, Pavord ID. Clinical, radiologic, and induced sputum features of chronic obstructive pulmonary disease in nonsmokers: a descriptive study. Am J Respir Crit Care Med 2002;166:1078-1083.

52. Brightling CE, Ward R, Goh KL, Wardlaw AJ, Pavord ID. Eosinophilic bronchitis is an important cause of chronic cough. Am J Respir Crit Care Med 1999;160:406-410.

53. Brightling CE, Monteiro W, Ward R, Parker D, Morgan MD, Wardlaw AJ, Pavord ID. Sputum eosinophilia and short-term response to prednisolone in chronic obstructive pulmonary disease: a randomised controlled trial. Lancet 2000;356:1480-1485.

54. National Institutes of Health, National Heart Lund and Blood Institute. Update of the NHLBI/WHO Workshop Report: Global Strategy for Asthma Management and Prevention Issued January 1995. Global Initiative for Asthma. Bethesda, MD: National Institutes of Health, National Heart Lund and Blood Institute; Revised 2002. Document No. $02-3659$. 